\title{
Pyrotechnics in Fireworks
}

\author{
Hugo Ineichen* and Beat Berger ${ }^{a}$
}

\begin{abstract}
The paths artificial fireworks took from China to Europe and the subsequent development of such fireworks from religious miracles to exciting entertainment for spectators is shown. Some basic information about fireworks is presented. By using auxiliary substances, it is possible to produce differently colored light or smoke. The procedure to prepare a commercial firework display is described. Some of the most important articles and items used in firework displays are listed.
\end{abstract}

Keywords: Auxiliary substances · Berthold Schwarz · Compositions · Fireworks · Firework items

\section{Introduction}

\subsection{The Snow of China}

The birthplace of fireworks is found in China. Several centuries BC some Chinese herdsmen discovered that their fires burnt much more violently and lively by the addition of saltpeter. At this time these white crystals, which were found in the free nature, were called 'Chinese snow'. Chinese snow is the main component of black powder or gun powder. It delivers the necessary oxygen for a rapid burning of the two other components, sulphur, and charcoal.

In the 4 th century $\mathrm{AD}$ a description of different bonfires is found in the literature, e.g. Solstice and Midsummer fires [1]. It is not clear if these fires were supposed to drive away winter time or evil ghosts; in all cases these events were embellished or were given a more mystical touch by socalled 'fire pots'.

In the same period of time, the beginnings of 'military pyrotechnics' can be found. The originally top-secret fire compositions were disseminated gradually, on one hand to Japan and on the other hand to India and from there passing the Orient to Europe (Fig. 1). 'Bengal Fire', 'Greek Fire' and 'Roman Candle' are well-known names of firework articles still used today. They serve as reminders of the dissemination of fireworks [2].

\subsection{It Was Not Berthold Schwarz}

In the 12th century, the Chinese conquered Mongolia, with the use of rockets. These rockets contained as a charge either fire compositions or sharp objects. The propellant of these rockets was a variation of black powder, its components were saltpeter, sulphur, and charcoal. A whole century later, the monk Berthold Schwarz tried to manufacture golden ink with similar ingredients. His experiments resulted in a bang and the loss of the vessel he mixed the materials in. Schwarz survived, as well as the rumor that he was the inventor of black powder. The powder however derives its name from the black color of the charcoal.

\subsection{The Clergy Discovers the Pos- sibilities of Firework Displays}

The art of pyrotechnics branched out in two directions. Both directions survive today. One branch focuses mainly on pyrotechnics for entertainment, the other one is concentrated on military applications. Florence, Italy, is thought of as the cradle of pyrotechnics for entertainment in Europe. The clergy soon liked what they saw at pyrotechnic demonstrations and also recognized the possibilities for religious purposes. The so-called 'wire-fire', an expression for rockets guided along a rope or wire, with their exhaust sparks was a favorable item. With this, the clergy could imitate the holy ghost or the punishing lightning of a supernatural power. A chronicler's quotation: "1379, Whitsuntide, a wire-fire rocket was guided towards the stage of a miracle play performance. The audience was so

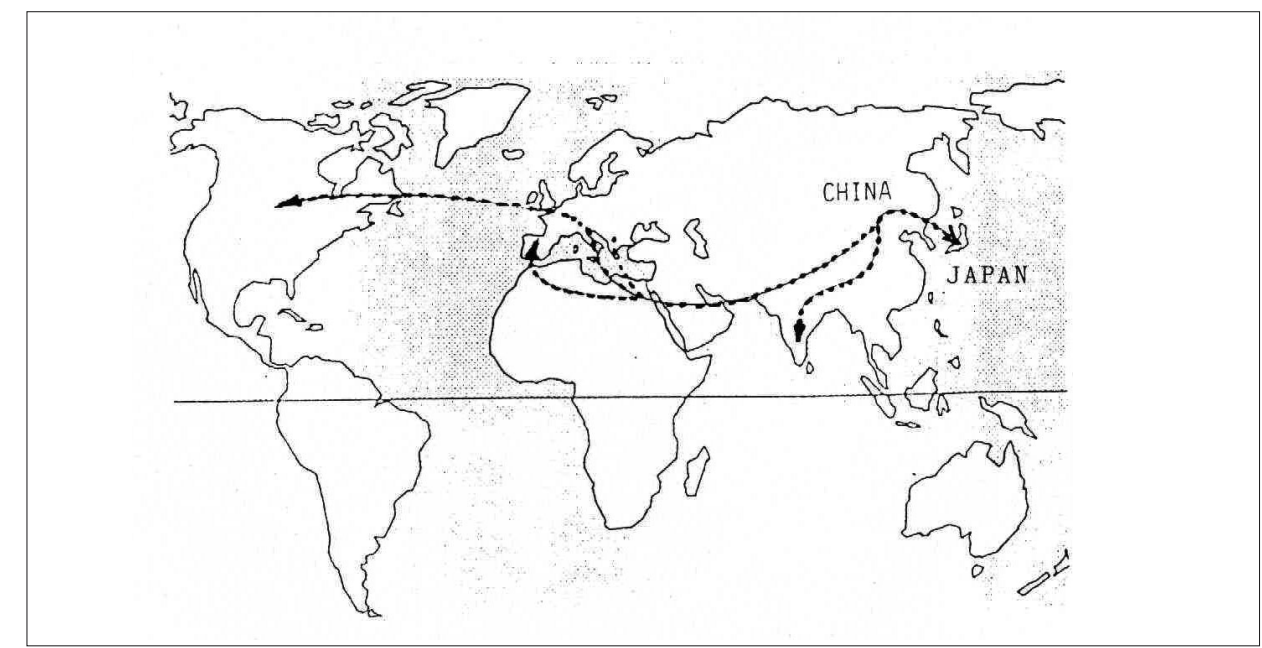

Fig. 1. Propagation of civilian fireworks 


\section{Ein ersetstlicb fpectaculum}

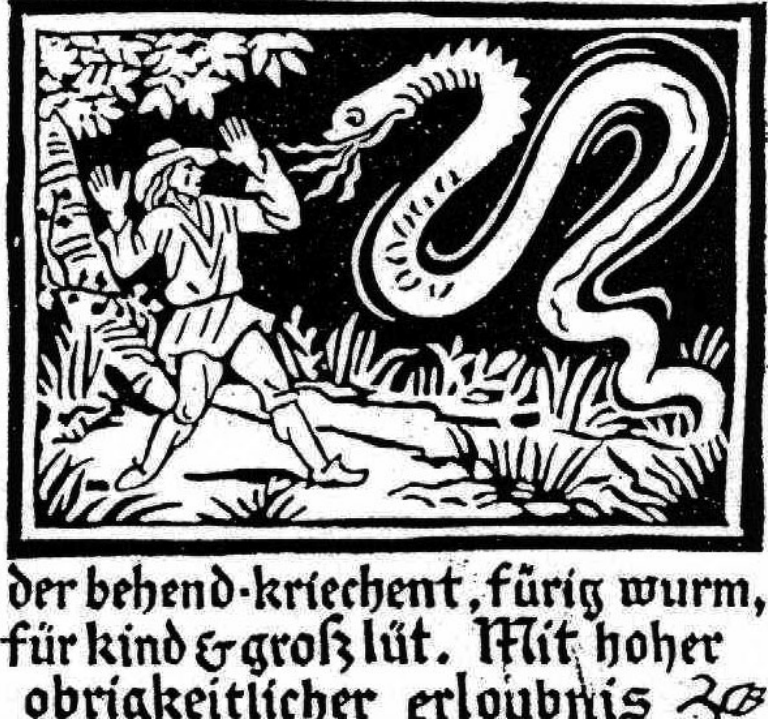

Fig. 2. Old label of crackers

much impressed and shocked by the moving and mysterious sparks and the noise that they fell to the ground and talked in confused languages".

\subsection{Like the Kiss of a Mistress}

During early times, simple and primitive items like rockets, jumping jacks, 'Bränder' and thunderstrokes were used (Fig. 2). Rotating devices like fire-wheels etc. did not become known until the middle of the 15 th century.

In the 'Fürwerckbuche' (Book of fireworks) published in 1540, Biringuccio mentioned such devices. The content of the book is concentrated mainly on military pyrotechnics, he categorizes civilian firework displays as something beautiful but very expensive, and of the duration of a kiss of a mistress - or even shorter... It was during that time that Saint Barbara was chosen as the patron saint of pyrotechnicians, fireworks experts, and mineworkers.

\subsection{From Miracle Plays to Händels Feuerwerksmusik}

In 1627, during a ceremonial act in Nancy, France, portraying the Hell with flashing lightning and the infernal flames, some of the spectators were so frightened, that they needed the help of a father confessor immediately afterwards.

After fireworks finally became accepted by the church and in miracle plays, royal courts became interested too. The era of the architectural or baroque fireworks was born. Models of castles, palaces and monuments as well as coats of arms and written words were constructed, loaded with fireworks and displayed in action at special oc- casions (Fig. 3). From Italy this tradition was taken over first by France and later found its way into the northern countries of Europe.

Fireworks combined with music is not an invention of today. George Friedrich Händel composed the famous 'Feuerwerksmusik' especially for a royal firework display. This took place in London in 1748 , to commemorate the peace treaty of Aachen. Besides the musicians, a unit of gunners had to fire 100 shots out of canons during the performance. The art of firework displays approached its culmination. Fireworks displays were used to celebrate victories, official opening of bridges and buildings, for bullfight spectacles and for many other events [3].

\section{From Abuses to Seenachtsfests}

Towards the end of the 18th century, commercial firework displays were used to attract guests and customers. Every gimmick was good enough to be used. Abuses like the following, published on a poster of an English resort, were common: "A bull laden with fireworks will be set free, even so a dog will be decorated with fireworks while a cat is tied up to the tail of said bull and the materials set on fire". Such cruelty to animals was soon forbidden by animal protection societies and the authorities. At the beginning of the 19th century such bad practices started to disappear in England, the audience became interested in other performances. In Vauxhall, England again, a unique show could be seen: 'The slide of Madame Sequi'. The lady was packed in fireworks and had a 150 meter long rope in front of her to slide down on, fully enlightened with sparks.... It took several decades to re-establish the seriousness of firework displays.

In Switzerland, firework displays as a people's attraction started in the 19th century. Tightrope-walkers balanced on the tightrope with a crate or box strapped to their back, which contained the firework display. Various resorts and hotels tried to attract guests and tourists with fireworks. In Oberried, a town on the Lake of Brienz, the 'Giessbachfälle', waterfalls cascading into the lake of Brienz, were illuminated with Bengal light which became a well-known attraction. This Bengal light or fire was supplied by people from Oberried. From this Bengal fire, a world-famous fireworks company developed. Cities fortunate to be located on the banks of a lake, started to burn off the firework displays on boats out on the lake. This was the beginning of the traditional lake firework displays as we still enjoy them today [2].

\section{How Does a Commercial Fire- work Display Become Reality?}

Before the artistic aspect of a firework display can be realized, plenty of administrative work and a lot of planning has to be accomplished. The localities where the display will take place have to be inspected, security and safety concepts must be worked out, the customer's ideas and financial possibilities must be discussed. After the customer's ok, the composition of the choreography and the artistic part of the display will begin. For this work, the knowhow and imagination of the pyrotechnicians, not only with respect of the available material, but also for the course of events and the possible color combinations is of great importance.

Like a classical theatre performance, firework displays are divided into different acts as well. Each act or picture is composed in such a way that towards the end a culmination of the effects occurs. The following pictures show an intensification of effects, colors and sounds up to the final climax, called the 'Schlussbouquet'. A script exactly defines the course of events, the materials in use and the sequence of the ignition of the different items. The script also makes clear where the various items like rockets, bombs, roman candles etc. are located, how the electric ignition wires are connected with each other and how the items are to be fired. The numerous and various ignition wires are numbered and connected to the equally numbered contacts in the ignition device. If everything is checked and double checked and 'ready to fire', the ignition of the individual pictures is activat- 

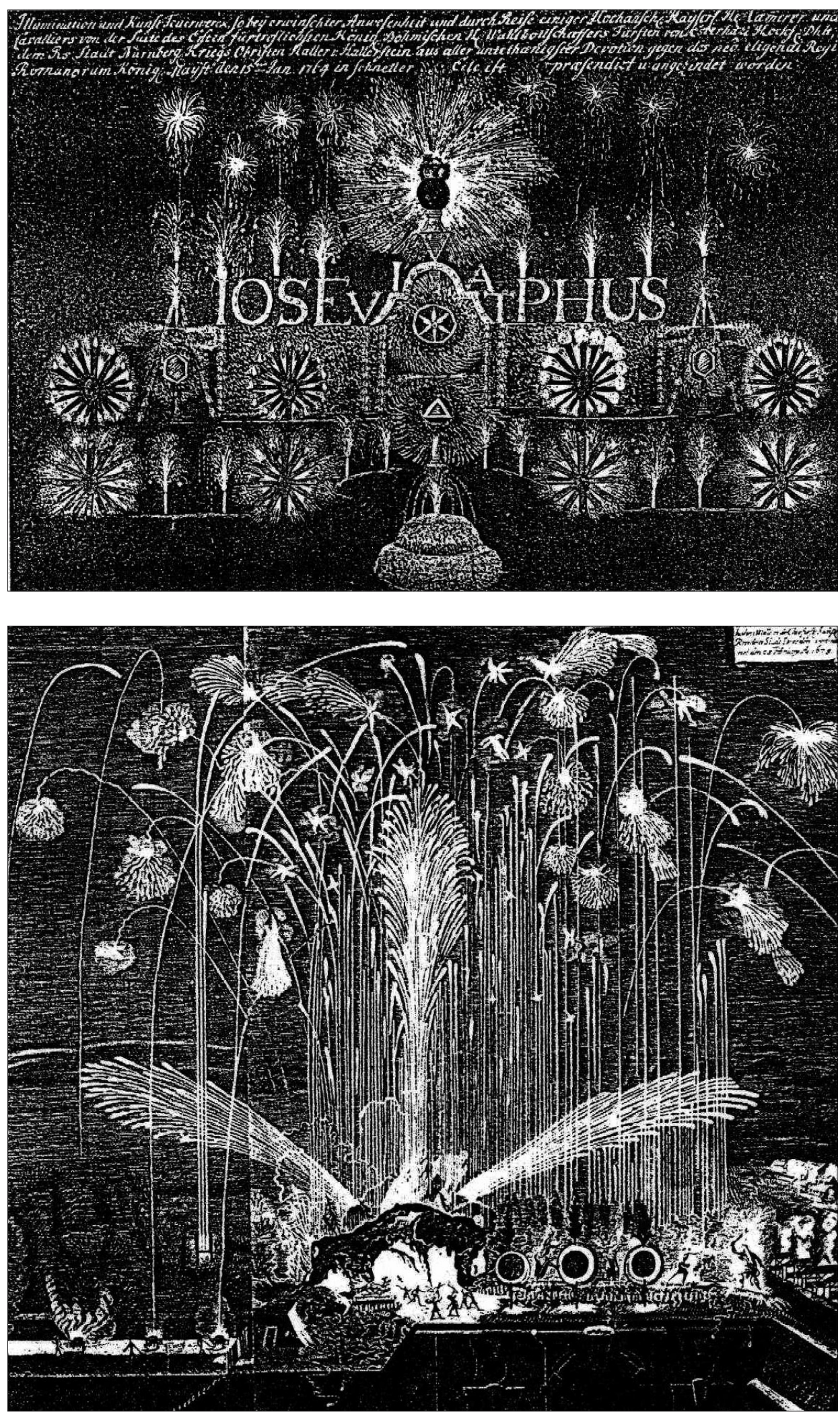

Fig. 3. Typical firework of the baroque period

ed by radio transmittance. This job is done by a pyrotechnician from the control room, which is some distance away from the display. The preparation and course of display is very laborious, most of the work is done behind the stage and not recognizable by the spectators. The joy and pride after a famous performance is immense within the organizers, specialists and

\section{Chemistry and Physics in Pyrotechnics}

Even today, pyrotechnicians are often looked at as magicians or sorcerers, but they are artists in the field of fire, color, and acoustics. Neither magic tricks nor witchcraft, but chemistry and physics are the basics of pyrotechnics, with its beautiful optical and acoustical characteristics.

a) Optical Effects:

Motion: rockets, fire wheels, bombs Color: stars, different colored smoke Sparks: candles, volcanoes, fountains

b) Acoustic Effects:

Bang: 'swissbangers', thunderbangers, crackers

Whistle: wailing banshees, sirens

Rustle: cracklestars

\section{Action Equals Reaction}

This important law of physics not only applies to diplomatic actions or general demonstrations, in the field of pyrotechnics it is also responsible for the motion of things.

a) Principle of Howitzers, Cannons, Mortars, Trench Mortars

A tube with one open end is charged e.g. with black powder. After ignition, a large mass of gases is produced. These gases propel the charge containing the pyrotechnic items high into the air. The charge is called a 'bomb' or 'grenade' and is equipped with a time fuse.

b) Principle of Rockets and Fire Wheels In a tube with one open end, the balance of pressure is disturbed during the burning of a solid propulsion element. The forces generated (gases) move the tube in the opposite direction to the open end (nozzle).

For a fire wheel, slow burning tubular propulsion elements are attached tangential to a disc which turns freely around its center.

The principles sound complicated but actually they are simple and work reliably [5].

\section{A Look into the Kitchen} of a Fireworker

\subsection{Colored Flames}

Substances which influence the color of helpers. After the 'show is over' the work for the fireworkers goes on. After the display, the launchers for rockets, bombs and all the other devices must be disassembled and loaded onto vehicles, cleaning work on the ground has to be done and also very importantly, the whole area must be checked for possible unexploded items [4]. a flame are mainly oxidizer-rich salts of alkaline- or alkaline-earth metals. Compositions containing such salts generate the desired colors.

Table 1 shows a synopsis of substances with emission in the visible light spectrum which are used for pyrotechnic application.

Mixtures, which burn off with a colorful flame, are known by the name of Bengal 
Table 1. Overview of the salts that are used to generate different colors

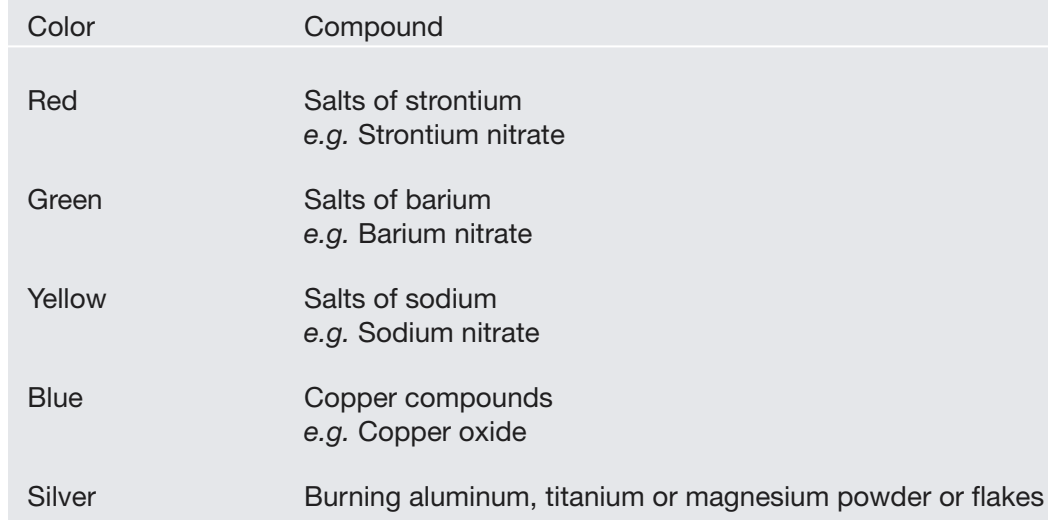

powders. They are used to illuminate e.g. buildings and sectors of land. They are also used in the theatre.

It is not possible to mix Bengal powders of different colors to get a new color. If yellow Bengal powder and blue Bengal powder is mixed, the emerging color is not green like in painting, but undefined and plain.

\subsection{The Touch to the Stars}

If a binder, e.g. dextrin or gum arabic, is added to Bengal powder and out of this mixture cylindrical or cubical objects are pressed, so-called 'stars' are generated. Of this mixture, spherical stars can be manufactured in a rotating drum. With layers of different colored Bengal powders, colorchanging stars emerge. When many of these stars are ignited simultaneously, so-called multicolored bouquets appear in the sky. Basic compositions in combination with the reducing agents magnesium or aluminum metal powder result in the so-called illuminating stars. Their very intense radiation and light emission is well known and finds application in firework displays as well as in the military field. Some of the most important parameters of stars and other effects in artificial fireworks are the type of oxidizer or the particle size of the reducing agent used.

\subsection{Why Wailing Banshees Wail and Some Stars Sparkle}

Towards the end of the 19th Century, firework displays with wailing effects were common. The reason why certain mixtures are able to generate acoustic phenomena when burned off in a tube with one open end was not understood for a long time. Weird theories were postulated. High-speed photography showed that the reason for this effect is found in the mechanism of the burning of the mixture. A so-called intermittent' burning of the mixture takes place. Many mega-fast small individual explosions occur, which makes the column of air in the tube oscillate, resulting in a wailing or howling sound. The frequency of the wailing sound decreases with longer tubes and increases with shorter tubes. If no tube is left above the pressed and burning mixture, no sound results [6]. The same princi-

Table 2. Pyrotechnic compositions generating different colored smoke

\begin{tabular}{|c|c|c|c|c|}
\hline Substance/Color & Blue & Green & Red & Yellow \\
\hline Potassium chlorate [wt.\%] & 28 & 28 & 25 & \\
\hline Potassium nitrate [wt.\%] & & & & 25 \\
\hline Sulfur [wt.\%] & & & & 16 \\
\hline Sudangelb & & 10 & & 59 \\
\hline Wheat flour [wt.\%] & 15 & 15 & 15 & \\
\hline Rhodamine B [wt.\%] & & & 24 & \\
\hline Para Red [wt.\%] & & & 36 & \\
\hline Methylene Blue [wt.\%] & 17 & 17 & & \\
\hline Indigo Pure [wt.\%] & 40 & 30 & & \\
\hline
\end{tabular}

ple is applied for the effects of the blinkand crackle-stars and the 'Blinklanzen'. Other formulations are used so that the frequency of the small individual explosions are slower and visible.

\subsection{Thunder and Lightning}

An important part of the display of fireworks are the elements of lightning, flashing, thunder and bang. A bang begins and one or more bangs end a classical firework display. The characteristics of many bombs is the so-called 'Endblitzknall' (final flashbang). Most of today's mixtures producing bangs are based on potassium perchlorate as oxygen supplier and a metal powder like aluminum, magnesium or even titanium [7]. Depending on the formulation, the powder will fizzle in an unconfined space and can be used as a flash-light for photographs or on stage. The same formulation can detonate in a confined space and displays a lightning flash and a loud bang.

\subsection{Colored Smoke Mixtures}

Beautiful colored smoke is produced by so-called colored smoke mixtures. These mixtures are used for firework displays during daytime or for signaling for military operations. A non poisonous, easy sublimating organic pigment is responsible for the color. Some colored smoke compositions proposed by Shimizu [5] are listed in Table 2.

\section{Listing of Firework Items}

Even for journalists it is not easy to find the correct description of the various fireworks items or articles. More often than not, everything that is shot into the sky during a fireworks display is referred to as a 'rocket'. In the following the most important articles and items used in fireworks displays are listed.

- Schweizerkracher: a small cardboard tube with both ends closed and filled with a 'bang-mixture' (Knallsatz). If ignited with a fuse, it explodes with a flashing bang. Schwärmer are similar to the Schweizerkracher, but filled with a slower burning mixture. This results in a winding movement with a sparkling tail.

- A 'final-bang'(Endknall) is also possible. Luftheuler und Pfeifen (wailing banshees and whistles) consist of a special mixture in a tube with an open end, making the column of air in the tube oscillate and thus resulting in a wailing or howling sound. Depending on the length of the column of air, a lower or higher pitch sound is produced.

- Bränder und Fontänen: A powder is pressed as a solid block into a tube. The burning surface and the thrust are small, 
the burning time is long. Bränder are used as propelling charges for rockets, fire-wheels, dragons, and similar items. A close relative of the Bränder is the Fountain, which disperses sparks of different appearance or colored stars.

- Rockets: A propellant charge, stabilized with a rod or fins, brings a cargo or payload into the sky. This payload will be dispersed at a predefined height by an expulsion charge. Innumerable display effects are possible. During the display, the rockets may be fired in series, in bundles or continuously out of a special launch pad. A good example are the favorite 'silver-bouquet rockets' found in the final picture of a display as cascading silver curtain.

- Vulkane und Vesuve (volcanoes and vesuvius): The powder is pressed into conical tubes. During the burning phase, the surface continuously grows and the sparks are ejected higher and higher. Volcanoes may be joined to form fans or other objects.

- Römische Kerzen (roman candles) propel continuously and in short intervals colored stars or small bomblets with a blazing and fiery tail into the sky. Beautiful gold- or silver-fans are obtained by specially arranged roman candles, mainly seen on bigger displays.

- Pot à feu oder Feuertöpfe (fire pots): Coloured stars, Schwärmer, whistles, wailing banshees and the likes are propelled with an expulsion charge out of a launching tube into the sky. They are used mainly for bigger firework displays together with bombs and roman candles.
- Fliegende Drachen oder Feuerkronen (flying dragons or crowns of fire) marking their way with a sparkling gold or silver spiral, the flying dragons wind themselves into the sky, ending with a colorful bouquet or a flash bang.

- Kugelbomben (spherical bombs) fascinate the spectators with the display of tens of thousands of stars in gold or silver or other colors. They form enormous pictures of flowers like chrysanthemums or palm trees. In addition to the immenseness of the display, the impression is created that the picture moves or falls towards the audience. Since most of the spherical bombs are imported from Japan, they are also known as 'Japan-bombs'.

- Zylinderbomben (cylindrical bombs) are launched like spherical bombs out of a tubular launcher. With these cylindrical bombs the possibility exists to create various effects high up in the sky within very short intervals. They usually end with a final flash bang.

- Bombenspiele - Bombenbatterien (game of bombs - batteries of bombs): The bombs are launched according to a defined timetable individually (regulated) to form a special effect, or fired all together simultaneously (unregulated) again to form a picture or effect.

- Granaten (grenades) are launched like bombs out of a launcher and the produced flash bang underlines the acoustics of the display.

- Lanzenstïcke (lancers): Flames of about $8 \mathrm{~mm}$ in diameter out of Bengal powder display figures, logos, symbols, and letterings during burning. There can be arranged in different colors in the same display and are optically very attractive. Because of the high cost to manufacture such displays, they are not often seen.

- Fire writing is more common than the use of lancers. It has a longer burning time and - importantly - works also when it's raining. The principle is inordinately large impregnated wicks like those used in candles. The figures, symbols etc. are arranged on an iron grille, the wicks are packaged waterproof and ignited electrically. The only color available is yellow-orange.

\section{Acknowledgements}

The authors thank Dr. Iris Rose and P. Mäder for the thorough review of this paper.

Received: March 30, 2004

[1] M. Websky, 'Lustfeuerwerkkunst', Verlag F. Hirt und Sohn, Leipzig, D, 1873.

[2] H. Ineichen, 'Kleine Feuerwerkdokumentation', H. Hamberger AG, Oberried, CH, 1980.

[3] G.W. Weingart, 'Pyrotechnics', Chemical Publishing Co. Inc., Brooklin, USA, 1947.

[4] A. Eschenbacher, 'Die Feuerwerkerei', A. Hartlebens Verlag, Leipzig, D, 1925.

[5] T. Shimizu, 'Fireworks - Art, Science and Technique', Maruzen Co. Ltd., Tokyo, J, 1981.

[6] R. Lancaster, T. Shimizu, R.E.A. Butler, R.G. Hall, 'Fireworks - Principles and Practice', Chemical Publishing Co. Inc., New York, USA, 1974.

[7] A.P. Hardt, 'Pyrotechnics', Pyrotechnica Publications, Post Falls, USA, 2001. 